Revista Mídia e Cotidiano

Editorial

Volume 13, Número 2, agosto de 2019

\title{
O imaginário e o cotidiano em contextos midiáticos: um diálogo com a obra de Michel Maffesoli
}

\section{Renata Rezende RIBEIRO ${ }^{1}$ Denise Cristina Ayres GOMES ${ }^{2}$}

"Quando nada é importante, tudo tem importância", eis a premissa da vida cotidiana e do imaginário sensível para o sociólogo francês Michel Maffesoli, considerado um dos maiores pensadores da pós-modernidade. Segundo o teórico, a complexidade do mundo pós-moderno demanda a criação de novas reflexões, em uma perspectiva que dê conta da diversidade do homem comum, em sua vivência ordinária. Trata-se, nesse sentido, de estar atento à vida banal, aos rituais, aos jogos de aparência, às sensibilidades coletivas.

Conhecido pela popularização do conceito de tribo, Maffesoli desenvolveu diversas pesquisas em torno da ligação social comunitária e da prevalência do imaginário nas sociedades contemporâneas, voltando o olhar para múltiplas culturas que constituem o que ele denomina de sociedade pós-moderna. O dossiê especial desta edição rende homenagem ao autor, apresentando diferentes perspectivas da obra de Maffesoli nas pesquisas brasileiras, particularmente no campo da comunicação e nos estudos de mídia.

No artigo que abre o dossiê, "Michel Maffesoli e a pós-modernidade como fenômeno de comunicação", Juremir Machado examina a noção da sociedade pósmoderna como expressão de uma rede de comunicação em ato. Para Machado, Maffesoli "observa o mundo vivido com uma lente cristalina e constantemente polida, como se ele

\footnotetext{
${ }^{1}$ Professora e vice-coordenadora do Programa de Pós-Graduação em Mídia e Cotidiano da Universidade Federal Fluminense. Doutora em Comunicação e Pós-Doutora em Comunicação e Cultura. Realizou pesquisa de pós-doutorado (com bolsa Capes) na Université René Descartes, Paris V/Sorbonne, sob a supervisão do professor Michel Maffesoli. Coordenadora do Grupo de Pesquisa Multis - Núcleo de Estudos e Experimentações do Audiovisual e Multimídia. E-mail: renatarezender@yahoo.com.br.

${ }^{2}$ Professora Adjunta e membro do corpo permanente do mestrado em Comunicação da Universidade Federal do Maranhão, campus Imperatriz. Pós-doutora em Mídia e Cotidiano e doutora em Comunicação Social. Coordenadora do Grupo de Pesquisa "Imaginarium - Comunicação, Cultura, Imaginário e Sociedade". E-mail: dayres42@gmail.com.
} 


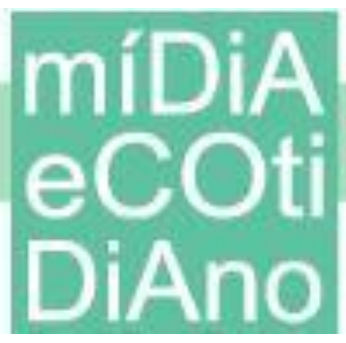

fosse um artesão obsessivo", e considera que a noção de pós-modernidade é uma importante ferramenta para se descrever o cotidiano, principalmente na passagem dos séculos XX ao XXI.

Já o texto "Discurso sobre a sociologia a contrapelo: senso comum e antitomismo na obra de Michel Maffesoli”, Fábio Castro analisa os pressupostos gerais do pensamento do sociólogo francês, interpretando-o como um tensionamento com a epistemologia enquanto forma de conhecimento. No artigo, Castro propõe uma reflexão da obra de Maffesoli como uma hermenêutica diatópica, a partir da revisão dos elementos que estruturam o pensamento do autor, entre eles, a crítica ao dualismo esquemático e a sensibilidade relativista.

Em "Maffesoli e Heidegger: a fenomenologia comum do ver por si mesmo", Eduardo Portanova realiza uma aproximação teórico-conceitual do sociólogo com o filósofo alemão. De acordo com Portanova, ambos autores, mesmo com diferenças, propõem uma leitura ensaística sobre a facticidade ontológica no espaço-tempo “societal". Nesse sentido, o imaginário é tomado para além de um aparato tecnológico acabado ou um problema de método, mas como "o entre-dois da natureza humana".

A temática do sagrado é igualmente recorrente na obra de Maffesoli, que considera que a saturação do mundo moderno marca também o retorno do sacral por meio da necessidade das comunhões emocionais, das tribos, da reconexão com o outro social, mas também do divino. Carlos Eduardo Souza Aguiar realiza uma releitura maffesoliana da modernidade como a época do desencantamento do mundo, retomando as análises clássicas de Max Weber. No texto "O lugar do sagrado no pensamento de Michel Maffesoli", Aguiar analisa o papel das novas tecnologias no processo de "reencantamento do mundo", a partir da noção de pós-modernidade e da sinergia entre os fenômenos arcaicos e técnicos propostos pelo autor francês.

Maffesoli dedica um livro para discutir a noção de "Ecosofia", ou sabedoria do habitat, da casa comum. O termo, que já aparece na obra de Fourier, consiste em um desdobramento do pensamento ecológico das décadas de 1960 e 1970 e ganha contornos característicos na obra maffesoliniana. A sensibilidade ecológica é concebida a partir do arquétipo de Dionísio, deus ctoniano, aquele que sabe aproveitar os frutos da terra. Dionísio também é o deus que rege a pós-modernidade, ambiente complexo e paradoxal. 
O artigo "A ecosofia de Michel Maffesoli e suas implicações tecnocomunicacionais" de Daiana Melo da Silva discute a noção de ecosofia partindo de um paradoxo. Ao mesmo tempo em que as tecnologias comunicacionais são vetores de comunhão e propiciam uma atmosfera emocional, aprofundam o processo de devastação do mundo natural, característico do pensamento racionalista moderno. O texto se propõe a pensar a ecosofia de forma holística e relacional, integrada às práticas cotidianas. Isso implica abordar a sabedoria do habitat e os modos de existência tecnológicos.

A sociologia do cotidiano deve perceber e escutar o que vem de baixo, atenta à transfiguração do social sob novas formas de comunicar, habitar e produzir cultura e política. Essa é a proposta do artigo "Transfiguração e Sexualidade: a herança "suja" de Michel Maffesoli para os estudos do cotidiano” de Marcello Monteiro Gabbay. O texto procura compreender as formas mais contundentes na nova política do cotidiano. Tais manifestações reúnem aspectos da visão maffesoliana como o clima festivo, as vinculações, os corpos e o desejo da comunicação.

Partindo de canções populares com temas ligados às sexualidades, o estudo revisita o pensamento de Maffesoli e observa o fenômeno da ascensão do conservadorismo no âmbito das instituições políticas como uma faceta do arcaísmo moderno e se debruça sobre a produção de discursos de ruptura e resistência. O lado "sujo" do cotidiano evoca o que há de mundano, dionisíaco e, portanto, criativo e transgressor, típico da herança do pensamento maffesoliniano.

"A postagem de nudes na plataforma Facebook sob a ótica do neotribalismo" é o título do artigo de Cynthia Correa e Carolina Murad. Trata-se de um estudo de caso da comunidade "Ousadia permitida", que busca compreender a prática do nudes através da publicação de relatos íntimos escritos ou em imagens como as selfies. O fenômeno é uma forma de se relacionar em comunidades virtuais de natureza tribal e marca o imperativo de visibilidade do sujeito pós-moderno.

A noção de tribo, extensamente tratada na obra de Maffesoli, é o leitmotiv do estudo que observa o fenômeno do nudes como uma construção de si legitimada a partir das trocas entre os usuários. Dessa forma, fragmentaram-se os limites entre o público e o privado, possibilitando um "eu" em constante modulação, exposto ao olhar do outro e 


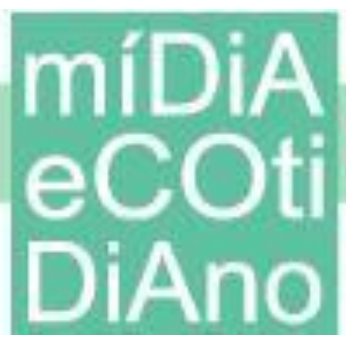

procurando um momento de celebridade. O desejo de estar junto é o motor erótico que causa identificação e agrega.

No artigo "O feminismo como ator-rede nas transformações do processo da comunicação", Marcia Eliane Rosa e Talita Bristotti Pereira da Silva partem da noção de ecosofia de Maffesoli para dialogar com a teoria do Ator-Rede de Bruno Latour, a fim de compreender o ativismo feminista no espaço digital. As autoras descontroem o binômio sujeito-objeto, característico da modernidade, para centrar-se na interação entre o sujeito, a tecnologia e a cultura.

O estudo possui caráter quantitativo e observa os temas feministas que se destacam nas redes digitais desde 2004, quando o tópico feminismo começa a ter destaque, até março de 2018. A noção de ecosofia e a Teoria Ator-Rede são fundamentais para abordar o net-ativismo. A primeira compreende as relações entre o homem e os elementos constituintes da sociedade como uma forma natural e não mais de dominação. Já a Teoria Ator-Rede possibilita pensar nesses elementos como produtores de uma ação.

Por fim, o dossiê sobre Maffesoli apresenta o artigo "It's a match! You and Rio have liked each other': uma análise da representação identitária de estrangeiros no Tinder sob a luz da sociologia do cotidiano e do imaginário" dos autores Naiara Silva Evangelo e Robson Braga. A partir da sociologia do cotidiano e imaginário, o artigo objetiva entender como os imaginários culturais atravessam interações interculturais. $\mathrm{O}$ estudo integra a pesquisa que investigou as experiências de cidade e de sociabilidade desses viajantes a partir de interações iniciadas no Tinder.

Unindo a observação das representações no aplicativo e a experiência de campo com usuário estrangeiro fora do Tinder, o estudo compreende que as autoapresentações na plataforma remetem a imaginários. A sociedade, como ressalta Maffesoli em suas obras, é uma comunidade de ideias, portanto, o que liga os homens é a forma comum de pensar, de representar as coisas. Os usuários estrangeiros do Tinder se posicionam e constroem suas personas virtuais por meio de símbolos, imagens e imaginários que remetem a alguma identidade nacional ou cultural, ainda que o objetivo seja estabelecer interações em outro local.

Nesse panorama, podemos perceber que o pensamento fértil de Michel Maffesoli é propício a várias interlocuções: o imaginário, o papel do emocional, o retorno 


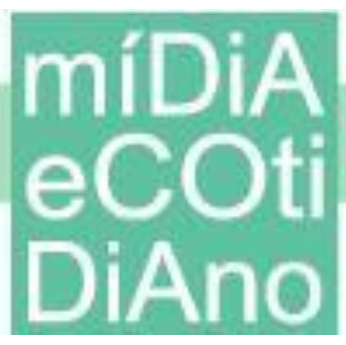

aos ritos, as reflexões sobre o tribalismo e o nomadismo, o sagrado, entre outros. Seja como teoria ou método, o pensamento de Maffesoli reflete a leitura atenta de nossa época, ambientada em processos midiatizados em plena transformação.

Além dos artigos publicados no dossiê temático, a revista traz mais quatro textos em sua seção livre. O primeiro artigo, "Fato ou Fake? A cobertura do G1 sobre o uso do WhatsApp no processo eleitoral para o Governo do Rio de Janeiro em 2018" (de Diego Santos Vieira de Jesus e Adriane Figueirola Buarque de Holanda), discute como o G1 noticiou a veiculação de notícias acerca das últimas eleições estaduais no Rio de Janeiro. O estudo complexifica questões acerca da cobertura política midiática já que, apesar do caráter conhecidamente manipulador do Grupo Globo, a seção Fato ou Fake exerceu um papel importante para a verificação da veracidade das notícias naquele contexto. Já o segundo texto, “\#Rocinha: A Representação no Instagram da maior favela do Brasil" (de autoria de Paulo Henrique Soares Almeida e Celia Mota), oferece uma análise acerca das formas em que as novas tecnologias oferecem oportunidades para uma representação mais múltipla e menos estereotipada da Rocinha. Os autores apontam que através de plataformas como o Instagram, mais imagens produzidas através de um senso de memória coletiva podem ser postadas por pessoas que moram ou visitam a comunidade e estão mais interessadas em registrar as pequenas alegrias cotidianas do que a violência. No artigo "O Agrotóxico não é pop: Como as narrativas hegemônicas e contra hegemônicas constroem os processos de comunicação entre campo e cidade" Juliana Dias Rovari Cordeiro analisa como a vinculação entre o sistema alimentar e o sistema midiático pode contribuir para enfraquecer nossa capacidade de contextualizar e englobar problemas como a fome e as desigualdades. Finalmente, no texto "Instagram Stories como suporte para comunicação patrocinada ou não-patrocinada: Estudo de caso Hugo Gloss" (de Luis Henrique Rauber e Manuela Albornoz Gonçalves), os autores revelam as maneiras em que as diferenças entre conteúdo patrocinado ou não patrocinado se tornam menos explícitas, já que o diferencial está na estratégia do influenciador, bem como em sua experiência pessoal e acadêmica.

Esperamos que apreciem a leitura!

Renata Rezende Ribeiro e Denise Cristina Ayres Gomes (Editoras da Seção Temática) Andrea Medrado e Denise Tavares (Editoras Chefes da Revista Mídia e Cotidiano) 